\title{
Non-Ligature Injuries in Suicidal Hanging: A Retrospective Study from South and South-East Delhi, India (2006-2014)
}

\author{
Asit Kumar Sikary, MBBS, M.D \\ Senior Resident Doctor, \\ Department of Forensic Medicine \& \\ Toxicology All India Institute of Medical \\ Sciences (AIIMS), New Delhi, India \\ bad.snmc@gmail.com

\section{Chittaranjan Behera , MBBS, M.D}

Assistant Professor,

Department of Forensic Medicine \&

Toxicology All India Institute of Medical Sciences (AIIMS), New Delhi, India drchitta75@yahoo.co.in

\section{Rajesh Kumar}

Senior Resident, Department of Forensic Medicine \& Toxicology All India Institute of Medical Sciences (AIIMS), New Delhi, India drrajesh_mmc@yahoo.com

\author{
Sarvesh Tondon
}

Associate Professor, Department of Forensic Medicine, VMMC \& Safdarjung Hospital, New Delhi, India sarvesh.tandon@yahoo.in

\section{Ravi Rautji, MBBS, M.D}

Professor,

Department of Forensic Medicine \& Toxicology, AFMC, Pune, India rautjiravi@hotmail.com

\section{Sudhir Kumar Gupta, MBBS, M.D , DNB}

Professor \& Head, Department of Forensic Medicine \& Toxicology All India Institute of Medical Sciences (AIIMS),

New Delhi, India

sgupta52001@yahoo.co.in

Abstract: Normally in suicidal hanging, only characteristic ligature mark(s) is present on the neck. However, the presence of other injuries on the body of deceased raises suspicion about the manner of death. The present study is a retrospective analysis of injuries present on the deceased other than ligature marks (non-ligature injuries) in suicidal hanging cases, which were autopsied at the All India Institute of Medical Sciences, New Delhi, India, during a nine-year period from 2006 to 2014. The cases were analyzed with regard to sex, age, nature of injury, location, and the circumstances in which the injuries were produced. Out of total 2,409 suicidal hanging deaths, in 119 (4.93\%) cases, non-ligature injuries were present. Males (56.03\%) outnumbered females (43.7\%). The commonest age group involved was 21-30 year (48.7\%). The most common injury was abrasion (42.9\%). The most common body part involved was upper limb (45.4\%). In most of the cases, injuries were sustained during bringing down the body for the purpose of rescue by relatives (29.4\%) and by self-infliction (28.6\%).

Keywords: Non-ligature injury, suicidal hanging, abrasion, self inflicted.

\section{INTRODUCTION}

Hanging is mostly suicidal. Accidental hanging is rare, while homicidal hanging is the rarest $[1,2]$. Accidental hangings are usually reported in autoerotic practices [3-5]. Only few cases of homicidal hangings have been reported in forensic literature [6-8].

In hanging death, the ligature mark on the neck is the main findings and its characteristics are well described in literature. Sometimes, injuries are found around the ligature mark known as periligature injuries which are caused by rope burns and nail marks. Few authors have discussed medico legal significance of periligature injuries in suicidal hanging $[9,10]$.

Apart from the characteristic ligature mark and periligature injury by rope burns, injuries are present on the other parts of body of a suicidal hanging victim. These injuries raise suspicion about the manner of hanging and mislead the investigation when wrongly interpreted. To avoid this, correct interpretation of these injuries is essential. In the present study, we have analysed these suspicion raising injuries in suicidal hanging. 


\section{MATERIAL \& METHODS}

This retrospective study was carried out in the Department of Forensic Medicine of All India Institute of Medical Sciences, New Delhi, India. All suicidal hanging cases for nine years (2006-2014) were studied. Detailed analysis of the cases was based on the inquest papers and evaluation of autopsy reports. Manner of death was confirmed as suicide after an investigation by the police. Antemortem fresh injuries which were inflicted within 24 hours prior to death on the body of the suicide victim, other than ligature mark(s) (here from non-ligature injuries) were analyzed.

\subsection{Observation}

Total 2,409 cases (1,556 males and 853 females) of suicidal hanging had been autopsied during that nine year period. Injuries to be studied were present only in 119 (67 male and 52 female) cases, which comprised of $4.93 \%$ ( $4.3 \%$ among male and $6.1 \%$ among female) of all suicidal hanging cases.

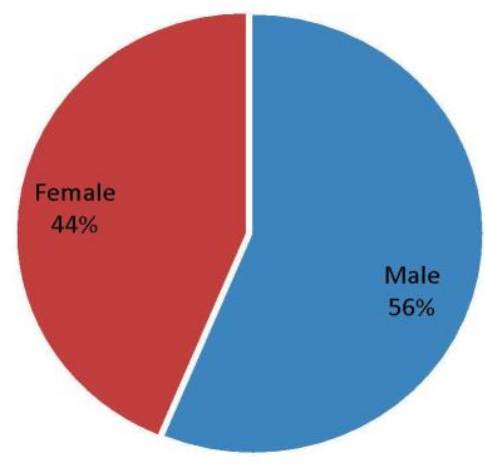

Figure1. Sex distribution of cases

The commonest age group involved was $21-30$ year $(50.5 \%)$ followed by $31-40$ years $(29.3 \%)$. The least numbers of cases $(2.0 \%)$ were reported in the 51-60 year age group.

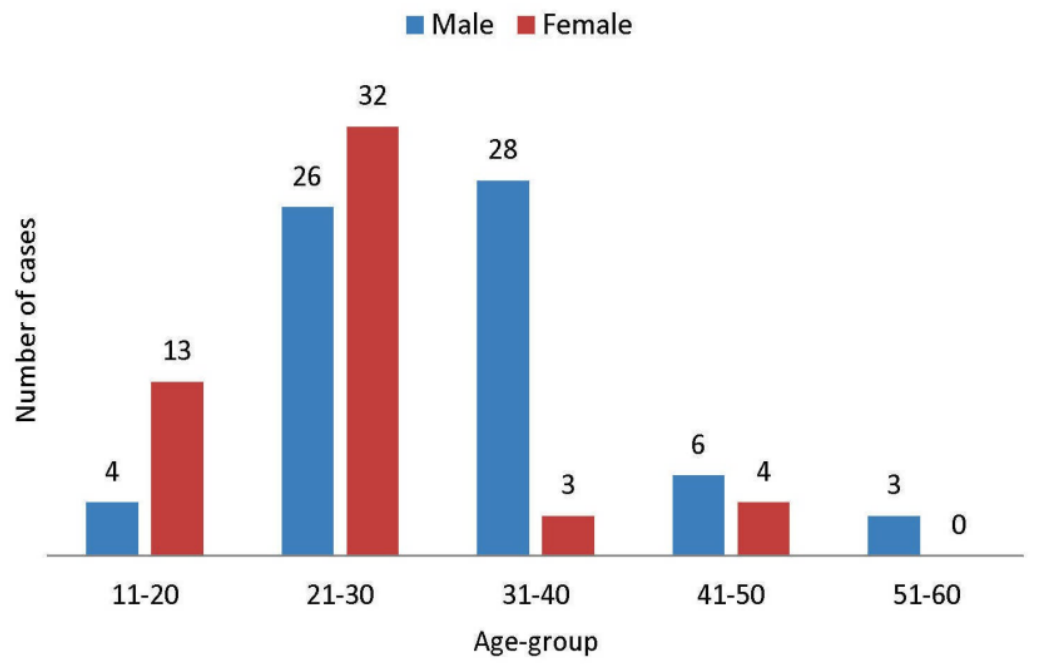

Figure2. Age distribution of cases

Most of the injuries were in the form of abrasion (42.9\%), followed by contusion (32.5\%), either alone or in various combinations with another type of injuries. The difference between the number of males and females for contusion was statistically significant $(\mathrm{p}=0.021)$.

Table1. Type of Injury

\begin{tabular}{|c|c|c|c|}
\hline Types & Male (\%) & Female (\%) & Total (\%) \\
\hline Abrasion & $39(48)$ & $27(38)$ & $66(42.9)$ \\
\hline Bite mark & $0(0)$ & $3(4)$ & $3(1.9)$ \\
\hline Contusion & $22(27)$ & $28(39)$ & $50(32.5)$ \\
\hline Incised wound & $9(11)$ & $10(14)$ & $19(12.3)$ \\
\hline Laceration & $10(12)$ & $4(6)$ & $14(9.1)$ \\
\hline Nail mark & $2(2)$ & $0(0)$ & $2(1.3)$ \\
\hline
\end{tabular}


The most common body region involved was upper limb (45.4\%) followed by lower limb (35.3\%) and head and face (31.9\%). Injuries over upper limb and head \& face and were more in females as compared to males, the difference was statistically significant $(\mathrm{p}=0.011)$ (Table 2). In 11 male and 28 females, multiple injuries were found over more than one region of the body, the difference between the two groups was statistically significant $(\mathrm{p}=0.002)$.

Table2. Body region distribution of injury

\begin{tabular}{|c|c|c|c|}
\hline Body regions involved & Male (\%) & Female (\%) & Total (\%) \\
\hline Head \& Face & $15(22.4 \%)$ & $23(44.2 \%)$ & $38(31.9 \%)$ \\
\hline Neck & $7(10.4 \%)$ & $5(9.6 \%)$ & $12(10.1 \%)$ \\
\hline Trunk & $9(13.4 \%)$ & $3(5.8 \%)$ & $12(10.1 \%)$ \\
\hline Upper limb & $25(37.3 \%)$ & $29(55.8 \%)$ & $54(45.4 \%)$ \\
\hline Lower Limb & $22(32.8 \%)$ & $20(38.5 \%)$ & $42(35.3 \%)$ \\
\hline
\end{tabular}

The most common mechanism for production injury was during the process of bringing down the victim for rescue and due to breakage of ligature (29.4\%) followed by self-infliction of injury (28.6\%). The injuries produced during bringing down the body was more common in male than female and the difference was statistically significant $(\mathrm{p}=0.007)$. Self-inflicted injuries were in the form of incised wounds over the wrist, lower part of the forearm of upper limbs and chest and abdomen. In one case, self inflicted nail mark was present on neck and lower part of the face. In 11 cases $(9.2 \%)$ the injuries were inflicted by others before suicide ( 2 male and 9 female). These injuries were in the form of abrasion, nail marks, bite marks and railroad contusions. The difference between male and female was statistically significant $(\mathrm{p}=0.007)$. In $5.9 \%$ cases the injuries were produced during the process of hanging. In 20 cases $(16.8 \%)$ circumstance of injury production could not be ascertained (Table 3).

Table3. Circumstances of Injury Production

\begin{tabular}{|c|c|c|c|}
\hline Mechanism & Male (\%) & Female (\%) & Total (\%) \\
\hline During the process of hanging & $6(9)$ & $1(2)$ & $7(5.9)$ \\
\hline During lowering down the body for the purpose of rescue & $25(37)$ & $10(19)$ & $35(29.4)$ \\
\hline During transportation to hospital & $6(9)$ & $1(2)$ & $7(5.9)$ \\
\hline During resuscitation & $1(2)$ & $4(8)$ & $5(4.2)$ \\
\hline Inflicted by others before hanging & $2(3)$ & $9(17)$ & $11(9.2)$ \\
\hline Self-inflicted & $21(31)$ & $13(25)$ & $34(28.6)$ \\
\hline Not known & $6(9)$ & $14(27)$ & $20(16.8)$ \\
\hline
\end{tabular}

\section{DISCUSSION}

There were total 2,409 suicidal hanging deaths (1,556 male and 853 female) during 9 year study period. Non-ligature Injuries were found in about $5 \%$ of cases $(n=119)$. A study by Sheikh et al. revealed that in 1 out of 86 cases, injury, other than ligature mark, was present on the body of a suicide victim [11]. Males outnumbered females in our study ( $\mathrm{M}: \mathrm{F}=1.3: 1)$. Males are generally heavier in built in comparison to females. While mobilizing the victim, there is more chance of sustaining injury in a heavy male body. Most of the injuries were found in the age group of 21-30 year, which may be because most of the suicide victims in our series were in this age group.

The injuries over the body of a suicide victim were mainly in the form of abrasion and contusion [12]. In this study, all types of injuries namely, abrasion, contusion, laceration, incised wound, bite mark and nail mark were found either alone or in various combinations. In about half of cases, abrasions were present and in about $40 \%$ of the cases, contusions were found. All non-ligature injuries were simple in nature.

Injuries were distributed all over the body. Upper limb followed by head and face was the common body region involved in both male and female. However, $44 \%$ females were having injuries over head and face while only $22 \%$ males were having injuries over head and face. In about one-third cases, multiple injuries were present over the body and females outnumbered males. Both the differences were statistically significant. The difference may be due to increased frequency of injuries inflicted on females by intimate partners.

In our study nail marks were present in two cases, in one case over the neck \& the lower part of the face and other case over the lower part of the face. During the process of hanging, probably the victim 
used his/her hands to release the constriction and the nail marks were produced. In a study by Sheikh et al. reported nail marks over neck in 2 cases of suicidal hanging [9]. Mohanty et al. found nail marks in one case of suicidal hanging in their study [12].

Injuries in hanging are mainly caused by self-infliction, erratic body movements during the convulsive phase of hanging, during transport to the health facility or during resuscitation. ${ }^{13}$ In our study, the injuries were caused during the process of hanging, during lowering down the body, during transportation, during resuscitation, self-inflicted and some of them were inflicted by others. Common mechanisms of the injuries were during the process of lowering down the body and by self-infliction in both male and female. Injuries caused during bringing down the body were present in $37 \%$ of males and $19 \%$ in females. The difference was statistically significant between the two groups. This might be because of heavy built of a male body and the person descending the body can easily lose control.

Self-inflicted injuries were present in $31 \%$ of male and $25 \%$ of female which is not unusual. Kerr et al. conducted a review on non-suicidal self-injuries and concluded that strong correlation exists between suicidality and self-injury [14]. Sometimes, a person hang himself after other form of suicide fails to produce death [12]. Presence of self inflicted injuries corroborates manner of death as suicide in hanging cases.

Injuries inflicted by others were present in about $9 \%$ of cases and females outnumbered males, the difference being statistically significant. These injuries were in the form of various combinations of abrasions, contusions, nail marks and bite marks. The injury patterns show involvement of physical violence in the form of slapping, pushing, kicking, biting, hitting, throwing objects, beating etc. All the female cases were assaulted by intimate partners.

Injuries can be sustained during the process of hanging. It could be because of the convulsive movements during the process of hanging and striking with the surrounding objects. The injuries are in the form of superficial abrasions and small contusions over bony prominence of the limbs and trunk due to contact of the body with nearby objects during voluntary or involuntary movements of the body [12]. Injuries could also be produced while falling down of the body during the act of hanging due to snapping of ligature material. As such, there were 7 cases in which injuries were sustained during the process of hanging.

Resuscitation injuries were present in 5 cases caused by external cardiac massage and were in the form of contusions and abrasions. The injuries produced during resuscitation can mislead about the manner of death, if not carefully interpreted [15].

In many cases, non -ligature Injuries are present in suicidal hanging cases. To prevent incorrect opinion, the forensic pathologist and investigating officer should know the characteristics and circumstances in which these injuries are sustained.

This is a retrospective study and all the information regarding demographic data and circumstances of production of injury in hanging was collected from the inquest papers and autopsy reports. No person was directly interviewed by the authors regarding the mechanism of causation of injuries. Hence, a prospective study is required for the detail analysis of mechanism of production of non ligature injury on suicide victims by hanging.

\section{REFERENCES}

[1] Sauvageau A. True and simulated homicidal hangings: a 6 year retrospective study. Med Sci Law 2009; 49(4):283-90.

[2] DiMaio V.J. Homicidal asphyxia. Am J Forensic Med Pathol 2000; 21(1):1-4.

[3] Verma S.K., Agrawal B.B. Accidental hanging with delayed death in a lift. Med Sci Law 1999; 39(4):342-4.

[4] Doychinov I.D, Markova I.M, Staneva Y. A. Autoerotic asphyxia (a case report). Folia Med (Plovdiv) 2001; 43(4):51-3.

[5] Vieira D.N, Da Siliva A.G, Accidental hanging during auto-erotic practices. Acta Med Port 1989; 2(3):154-7 
[6] Uneo Y., Fukunaga T., Nakagawa K., et al. A homicidal strangulation by ligature, disguised as a suicidal hanging. Nippon Hoigaku Zasshi 1989; 43 (1):46-51.

[7] Mallach H. J, Pollak S. Simulated suicide by hanging after homicidal strangulation. Arch Kriminol 1998; 202(1-2):17-28.

[8] Leth P., Vesterby A. Homicidal hanging masquerading as suicide. Forensic Sci Int 1997; 85(1):65-71.

[9] Tumram N.K, Ambade V.N, Bardale R.V., et al. Injuries over neck in hanging deaths and its relation with ligature material: Is it vital? Journal of Forensic and Legal Medicine 2014; 22:8083.

[10] Mohanty M.K., Rastogi P., Kumar G.P., et al. Periligature injuries in hanging. Journal of Clinical Forensic Medicine 2003; 10:255-258.

[11] Sheikh M.M.M., Chotaliya H.J, Modi A.D., et al. A Study of Gross Postmortem Findings in Cases of Hanging and Ligature Strangulation. Journal of Indian Academy of Forensic Medicine 2013; 35(1):63-5.

[12] Reddy K., Murty O.P. The Essentials of Forensic Medicine and Toxicology. 33rd ed. New Delhi: JAYPEE The Health Science Publishers; 2014:p345.

[13] DiMaio V., DiMaio D. Forensic Pathology. 2nd ed. London: CRC Press; 2001.

[14] Kerr P.L., Muehlenkamp J.J., Turner J.M. et al. Nonsuicidal Self-Injury: A Review of Current Research for Family Medicine and Primary Care Physicians. J Am Board Fam Med 2010; 23:240-259.

[15] Reddy K., Murty O.P. The Essentials of Forensic Medicine and Toxicology. 33rd ed. New Delhi: JAYPEE The Health Science Publishers; 2014:p468.

\section{AUTHORS' BIOGRAPHY}
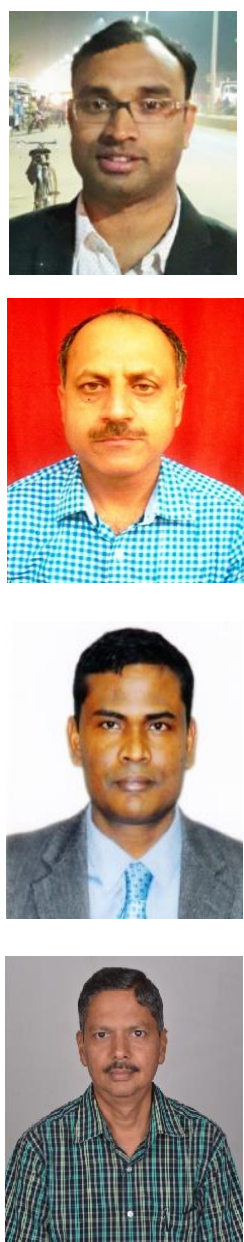

Dr. Asit Kumar Sikary, is an MD in Forensic Medicine from prestigious All India Institute of Medical Sciences, New Delhi, where he worked for six years. Now he is posted as Assistant Professor at ESIC Medical College, Faridabad in the department of Forensic medicine, where he is in-charge of the department. He has published articles in various national and international journals with social and scientific impact, some of which became a topic of discussion in various national newspapers.

Dr. Sarvesh Tondon, MD (Forensic Medicine), DNB Presently Associate Professor, Department of Forensic Medicine, VMMC \& Safdarjung Hospital, New Delhi-110029, India. Publications in indexed journal: 19. Examiner (UG, PG)VMMC \& Safdarjung Hospital,, New Delhi, SP Medical College, Bhopal, Mahatma Gandhi Institute of medical Sciences, Jaipur, Ruxmaniben Deepchand Gardi Medical College, Ujjain, S N Medical College, Agra and at Medical Colleges at Jodhpur, Indore etc.

Dr Chittaranjan Behera, MD (Forensic Medicine), AIIMS, MAMS, FIMSA, FICFMT. Presently Assistant Professor, Department of Forensic Medicine \& Toxicology, All India Institute of Medical Sciences, New Delhi-110029. Publications in indexed journal: 130. Reviewer: in scientific journals indexed in Pub Med like Injury Prevention, Journal of Burns, BMJ Case reports, Journal of Forensic and legal Medicine, Food and Chemical Toxicology, Med Sci and Law and other forensic journals etc. Area of special interest: Forensic Pathology \& Suicide biology.

Dr. (Col) Ravi Rautji, MBBS DHM MD (Forensic Medicine), Dip in Cyber Law (ASCL), PGDM (Torture Medicine), Formerly Prof and Head of Forensic Medicine and Toxicology, Armed Force Medical College, Pune. Presently commanding a hospital of Indian Army

Publications: (Total) 78, International Journals: 27 (25 indexed in Pubmed), National Journal: 51. Examiner (UG, PG)-MUHS, Ramchandra Institute of Medical Sciences, Chennai, DY Patil University, Bhartiya Vidyapeeth University, KLE University, Belgaum. Gujrat University, Kerala University of Health Sciences, AIIMS, New Delhi. 


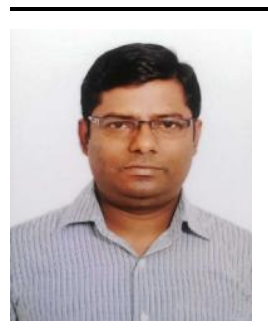

Dr. Rajesh Kumar, is working as a Senior Resident in the Department of Forensic Medicine and Toxicology, All India Institute of Medical Sciences. He did his MBBS from Madras Medical College, Chennai and MD (Forensic Medicine) from AIIMS, New Delhi.

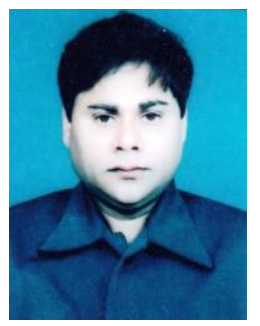

Dr Sudhir Kumar Gupta, MBBS (Gold Medal) MD (Forensic Medicine), DNB, FICFMT, FIAMLE. Presently Professor \& Head, Department of Forensic Medicine \& Toxicology, All India Institute of Medical Sciences, New Delhi-110029 Member, Editorial Board, International Journal of Research Foundation of Hospital \& Healthcare Administration, Member- International Advisory Committee of $3^{\text {rd }}$ International Congress of Asia Pacific Association of Medical Toxicology (APAMT) held at Malyasia. Appointed 4 times member, Dean Committee AIIMS, New Delhi. Area of special interest: Forensic Pathology \& Cadaveric organ retrieval 